\title{
Thermal, FT-IR and SHG efficiency studies of L-arginine doped KDP crystals
}

\author{
K D PARIKH, D J DAVE, B B PAREKH ${ }^{\dagger}$ and M J JOSHI* \\ Department of Physics, Saurashtra University, Rajkot 360 005, India \\ ${ }^{\dagger}$ Institute of Diploma Studies, Nirma University of Science and Technology, S.G. Highway, \\ Ahmedabad 384 481, India
}

MS received 22 January 2007; revised 12 March 2007

\begin{abstract}
Potassium dihydrogen phosphate (KDP) is a well known nonlinear optical (NLO) material with different applications. Since most of the amino acids exhibit NLO property, it is of interest to dope them in KDP. In the present study, amino acid L-arginine was doped in KDP. The doping of L-arginine was confirmed by FT-IR and paper chromatography. Thermogravimetry suggested that as the amount of doping increases the thermal stability decreases as well as the value of thermodynamic and kinetic parameters decreases. The second harmonic generation (SHG) efficiency of L-arginine doped KDP crystals was found to be increasing with doping concentration of L-arginine. The results are discussed here.
\end{abstract}

Keywords. NLO material; solution growth; doping; FT-IR; TGA; kinetic parameters; thermal parameters; SHG efficiency.

\section{Introduction}

Potassium dihydrogen phosphate $\left(\mathrm{KH}_{2} \mathrm{PO}_{4}, \mathrm{KDP}\right)$ and its isomorphous deuterated form, DKDP $\left(\mathrm{KD}_{2} \mathrm{PO}_{4}\right)$, are popular due to their applications in frequency converters, electro-optic switching and modulators (Lu and Sun 2002; Sun et al 2002). KDP and DKDP crystals have been grown in very large sizes up to $57 \times 57 \mathrm{~cm}^{2}$ in cross-section and about $55 \mathrm{~cm}$ in height (Zaitseva et al 1997). KDP and DKDP crystals have been developed for the world's most powerful laser systems (De Yoreo 2002). In order to get good quality crystals rapidly, many techniques have been introduced by several workers (Wang et al 1987; Zaitseva et al 1999; Dixit et al 2001).

Several authors have doped KDP crystals by KI, NaI and $\mathrm{Au}^{+}$(Ananda Kumari and Chandramani 2003), ammonium compounds (Freeda and Mahadevan 2000) and urea and thiourea (Priya et al 2001). It was found that the doping increased electrical conductivity of KDP crystals. Similarly, light scattering in KDP is found to be due to bacteria (Yokotani et al 1988), organic materials (Singleton et al 1988) and some indissoluble impurities (Yan et al 1986). Since all of amino acids, except glycine, exhibit NLO properties, the present communication is a part of the extensive studies being carried out on the effect of different amino acids doping on the properties of KDP. It has been reported that doping of L-arginine in KDP in-

\footnotetext{
*Author for correspondence (mshilp24@rediffmail.com)
}

creases NLO properties of KDP in terms of increase in second harmonic generation efficiency (SHG) (Kumaresan et al 2004). In that regard, the effect of doping of amino acid L-arginine on the thermal stability of grown crystals and the kinetic and thermodynamic parameters of dehydration as well as SHG efficiency is reported.

\section{Experimental}

\subsection{Crystal growth}

Slow evaporation technique was employed to grow crystals. The solubility curve of KDP in double distilled water was experimentally confirmed with the available one in the literature. The doping of L-arginine into KDP was achieved by adding 0.3 and $0.4 \mathrm{wt} \%$ solution into saturated KDP solution. The mixture was thoroughly stirred for $8 \mathrm{~h}$ for homogenization. Seed crystals were harvested in conventional manner. Best seed crystals of respective doping were selected and placed in appropriate solution for growth. The vessel containing the solution was closed with perforated cover and kept in a constant temperature bath at $40^{\circ} \mathrm{C}$ to allow slow evaporation of the solvent. Figure 1 shows a photograph of $0.3 \%$ L-arginine doped KDP crystal.

\subsection{Characterization}

The crystals were characterized by FTIR spectroscopy, powder XRD and thermogravimetric analysis (TGA). The 
FTIR spectra were recorded on BRUKER IFS 66V FTIR spectrometer in the range from $400-4000 \mathrm{~cm}^{-1}$. Powder XRD was obtained on a PHILIPS X'PERT MPD system. TGA was performed on a NETZSCH Geratebau $\mathrm{GmbH}$ from room temperature to $900^{\circ} \mathrm{C}$ at a heating rate of $15^{\circ} \mathrm{C} /$ min. The crystals were evaluated by the Krutz and Perry (1968) powder technique using a Q-switched, mode locked $\mathrm{Nd}$ : YAG laser. A micro-crystalline material of KDP, available at the Indian Institute of Science, was used for comparison in the SHG measurements.

\section{Results and discussion}

L-arginine is one of the amino acids widely found in the biological substances. It contains $\alpha$-amino and guanidyl groups (Karle and Karle 1964). The strong basicity of guanidyl group is considered to be responsible for the functioning in the living matter (Aoki et al 1971). Amino acids are promising materials for NLO application. Complexes of amino acids with inorganic salts are considered to be novel materials for second harmonic generation (SHG) properties and they are found most of the times to be as promising as KDP or better than it (Monaco et al 1987; Narayana Bhat and Dharmaprakash 2002). However, NLO properties of L-arginine diphosphate (Ittyachen and Sagayaraj 2002), L-arginine phosphate monohydrate (Jaing et al 1983), L-arginine perchlorate (Monaco et al 1987), Largininum dinitrate (Ramasamy et al 2001), and many other forms of L-arginine have been investigated.

Usually, amino acid is incorporated with inorganic group to develop semi-organic NLO (Ittyachen and Sagayaraj 2002) or inorganic crystal is doped by metallic ions, alkali halides or ammonium compounds (Freeda and Mahadevan 2000; Priya et al 2001; Ananda Kumari and Chandramani 2003), but no attempt is made on large scale to dope amino acid into KDP. However, only one report is available in which the doping of L-arginine in KDP was

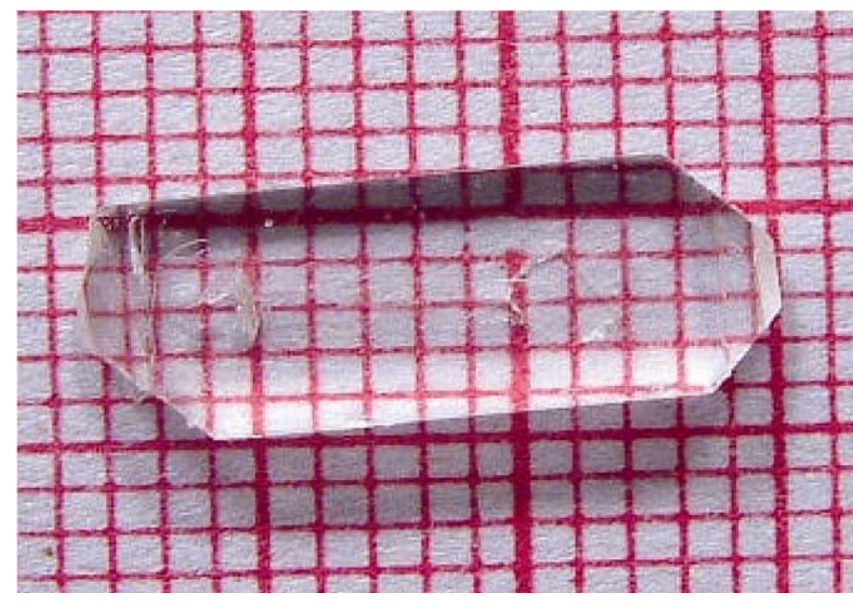

Figure 1. Photograph of $0 \cdot 3 \%$ L-arginine doped KDP crystal. done (Kumaresan et al 2004) and the SHG efficiency is reported to be increased by doping of L-arginine. Moreover, the effect of doping of amino acids, L-tyrosine (Meera et al 2001), and L-lysine (Mohan Kumar et al 2001), in TGS crystals has been investigated.

Figures 2-4 show the powder XRD patterns of pure KDP, $0.3 \%$ L-arginine doped KDP crystals and $0.4 \% \mathrm{~L}-$ arginine doped KDP crystals, respectively. The unit cell parameters were calculated by using the software powder $X$. The unit cell parameters are listed in table 1 . This suggests that the compound retains almost single phase structure and exhibits very slight variation on doping with Larginine.

The FT-IR spectrum of L-arginine doped KDP crystal is shown in figure 5 . The broad envelopes observed between 2300 and $3600 \mathrm{~cm}^{-1}$ are mainly due to $\mathrm{P}-\mathrm{OH}$ stretching of $\mathrm{H}_{2} \mathrm{PO}_{4}, \mathrm{O}-\mathrm{H}$ stretching of $\mathrm{COOH}$ and water of crystallization, $\mathrm{N}-\mathrm{H}$ stretching of $\mathrm{NH}_{3}^{+}, \mathrm{C}-\mathrm{H}$ stretching of $\mathrm{CH}_{2}$ and $\mathrm{CH}$. The broadness is generally considered to be due to hydrogen bonding interaction of $\mathrm{H}_{2} \mathrm{PO}_{4}^{-}, \mathrm{COOH}^{-}$and $\mathrm{NH}_{3}^{+}$with adjacent molecules. The $\mathrm{C}=\mathrm{O}$ stretching and $-\mathrm{C}=\mathrm{NH}_{4}$ stretching are revealed by minor absorption peak within $1750 \mathrm{~cm}^{-1}$. The $\mathrm{CH}_{2}$ bending attributes the absorption at $1302 \mathrm{~cm}^{-1}$. The absorption occurring at $1097.4 \mathrm{~cm}^{-1}$ and $910.3 \mathrm{~cm}^{-1}$ are due to $\mathrm{P}-\mathrm{OH}$ stretching. Intense $\mathrm{ab}-$ sorption observed at $536.2 \mathrm{~cm}^{-1}, 435.9 \mathrm{~cm}^{-1}$ and $413.7 \mathrm{~cm}^{-1}$ are due to $\mathrm{P}-\mathrm{OH}$ deformation. By comparing the spectra of doped and undoped crystals, one can easily find missing absorptions for $\mathrm{N}-\mathrm{H}$ stretching of $\mathrm{NH}_{3}^{+}, \mathrm{C}-\mathrm{H}$ stretching of $\mathrm{CH}_{2}$ and $\mathrm{CH}$ and conclude that L-arginine doping was successfully achieved. The paper chromatography of dissolved crystals using nin-hydrin exhibited purple spot, which is a clear indication of the presence of amino acid in the crystal.

For the measurements of SHG efficiency, the output of $\mathrm{Nd}$ : YAG Quantum ray laser was obtained through the crystalline powder sample. A Q-switched, mode-locked $\mathrm{Nd}$ : YAG laser was used to generate about $2.7 \mathrm{~mJ} /$ pulse at $1064 \mathrm{~nm}$ fundamental radiation. This laser device can be operated in two different modes. In the single shot mode, the laser emits an $8 \mathrm{~ns}$ pulse. While in the multi-shot mode, the laser produces a continuous train of $8 \mathrm{~ns}$ pulses at a repetition rate of $10 \mathrm{~Hz}$. In the present study, a single shot mode of $8 \mathrm{~ns}$ laser pulse with a spot radius of $1 \mathrm{~mm}$ was used. This experimental set up used a mirror and 50/50 beam splitter to generate a beam with pulse energies of about $2.7 \mathrm{~mJ}$. The input laser beam was allowed to pass through an IR reflector and then directed on the micro-crystalline powdered sample packed in a capillary tube of diameter, $0.154 \mathrm{~mm}$. The photodiode detector and oscilloscope arrangements measured the light emitted by the sample. Micro-crystalline powder of KDP or urea is taken in a similar capillary tube sealed at one end for comparison. The intensity of the second harmonic output from the sample is compared with that of KDP. In this manner, the figure of merit of SHG of the sample is estimated (Ambujam 


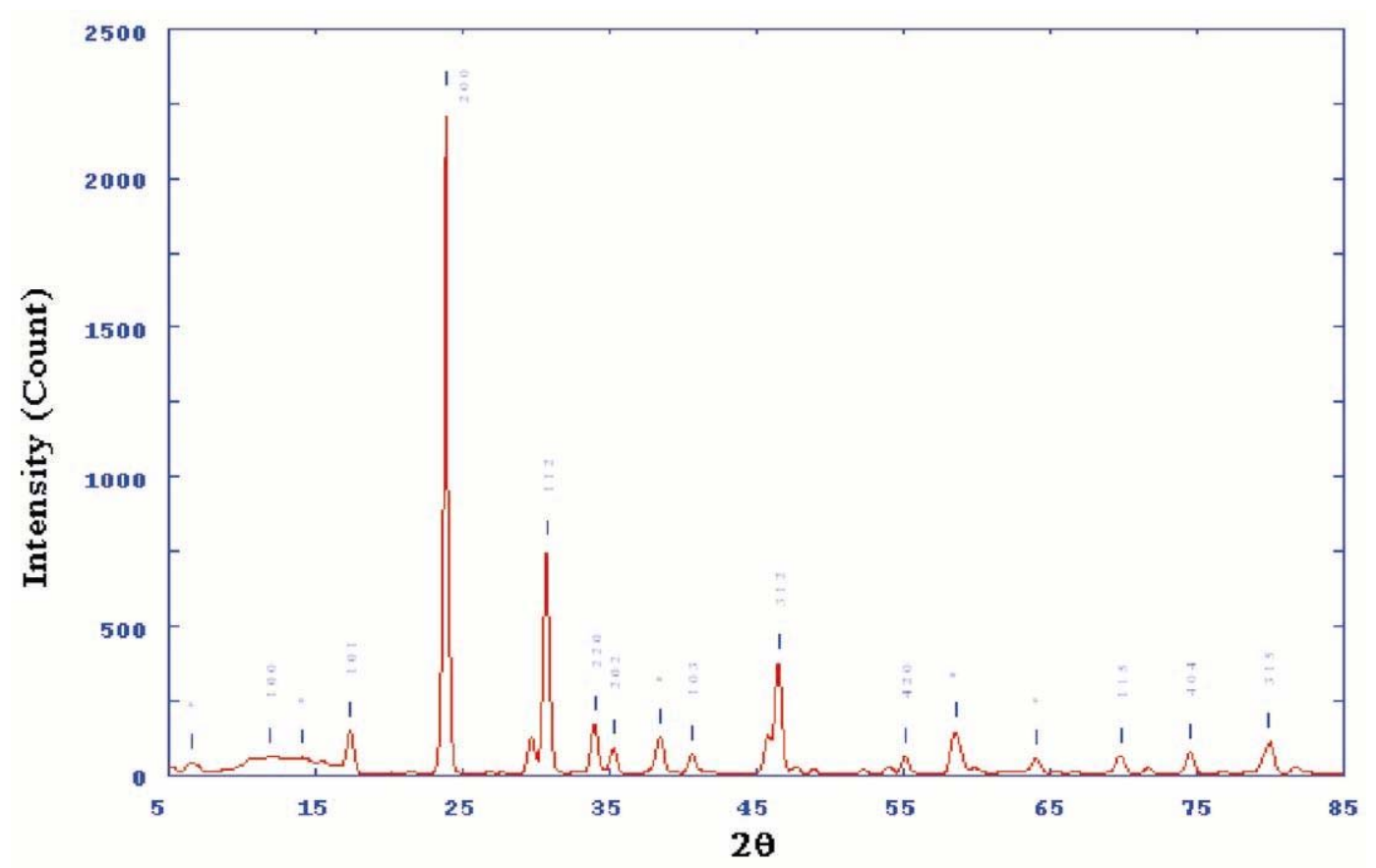

Figure 2. Powder XRD of pure KDP crystal.

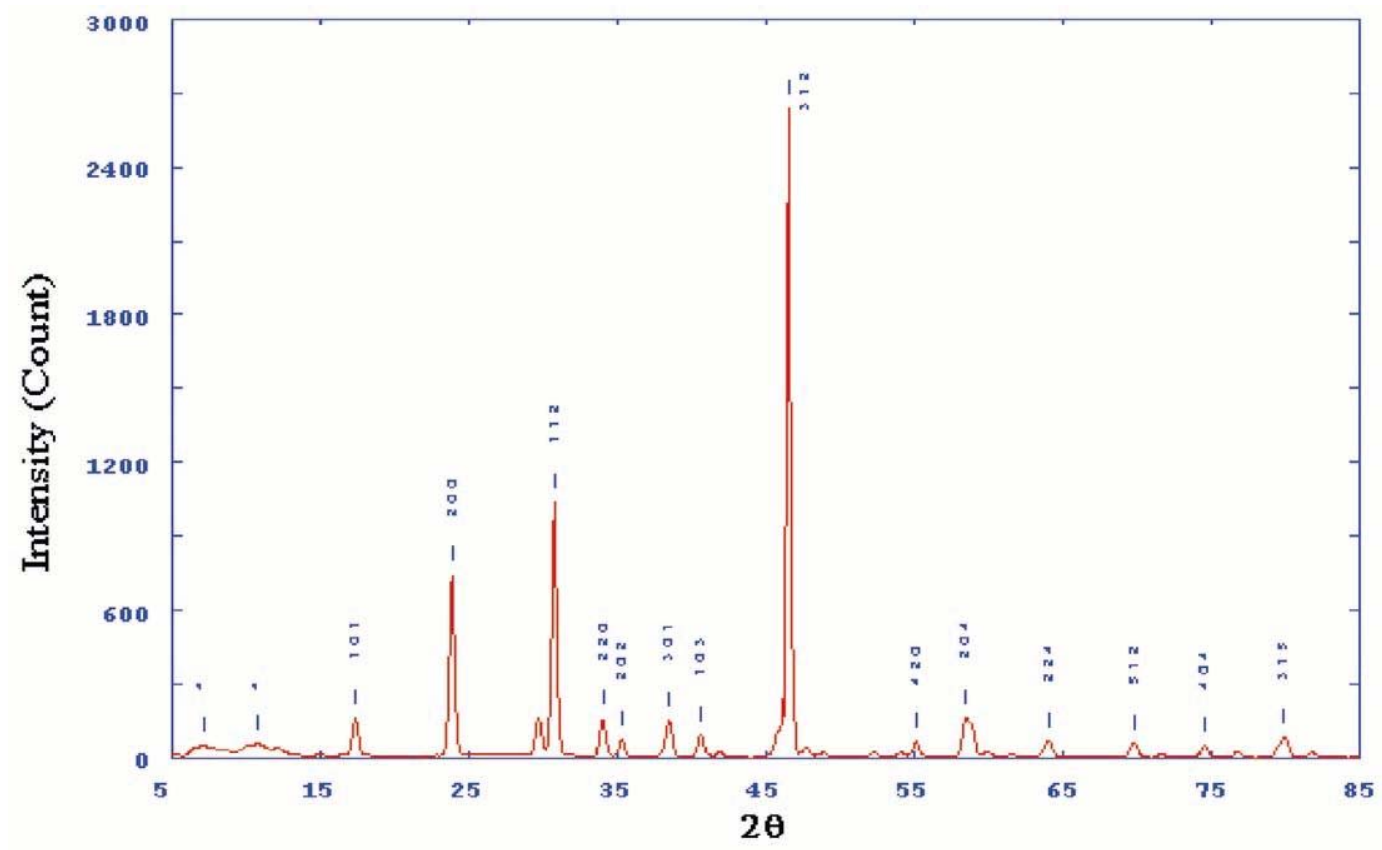

Figure 3. Powder XRD of $0 \cdot 3 \%$ L-arginine doped KDP crystal.

et al 2006). For the Nd: YAG laser the fundamental beam of $1064 \mathrm{~nm}$ generates second harmonic signal of $532 \mathrm{~nm}$. The output pulses were measured for different samples with reference to pure KDP (405 $\mathrm{mV})$ and the results are compiled in table 1 .

In the present investigation, the effect of L-arginine doping on thermal stability of KDP crystal is studied by employing TGA. Figures 6-8 indicate thermograms for pure KDP, $0 \cdot 3 \%$ L-arginine doped KDP and $0.4 \%$ Larginine doped KDP, respectively. It has been observed that initially crystal looses water of hydration and then becomes anhydrous and remains in that form up to the end of the analysis. One can notice from the thermogram that on increasing the level of L-arginine doping, the dehydration process starts early and the crystal becomes anhydrous faster than the pure KDP. Since amino acid becomes un- 


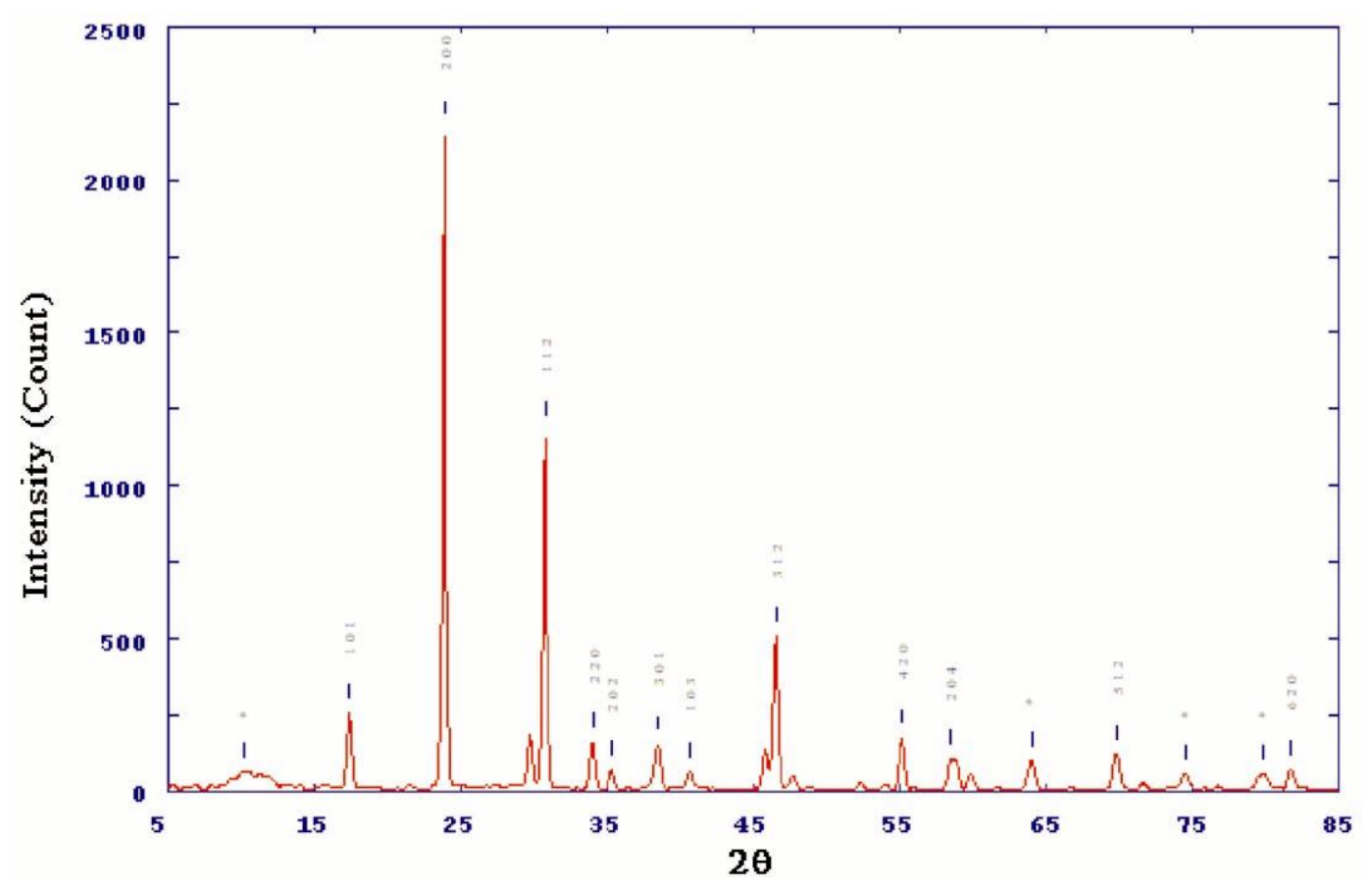

Figure 4. Powder XRD of 0.4\% L-arginine doped KDP crystal.

Table 1. Unit cell parameters and SHG data of pure and doped KDP.

\begin{tabular}{lccccc}
\hline & \multicolumn{2}{c}{ Unit cell parameters } & & Second harmonic \\
\cline { 2 - 3 } Samples & $a=b(\AA)$ & $c(\AA)$ & & signal output (mV) & SHG efficiency \\
\hline Pure KDP crystal & 7.457 & 6.976 & 405 & 1 \\
KDP + 0.3\% L-arginine & 7.453 & 6.975 & 540 & 1.33 \\
KDP + 0.4\% L-arginine & 7.453 & 6.975 & 705 & 1.74 \\
\hline
\end{tabular}

stable at lower temperature, it weakens KDP crystal and as a result the dehydration process takes place early and faster as compared to pure KDP. This also proved that the amino acid has entered KDP crystal lattice in doped form.

The use of thermogravimetry data to evaluate the kinetic parameters of solid state reaction involving weight loss has been investigated by many workers (Coates and Redfern 1964; Dabhi and Joshi 2003; Joshi and Joshi 2003). Very often the pyrolysis occurs through a many-stepped mechanism. The shape of the curve is determined by the kinetic parameters of pyrolysis such as order of reaction, frequency factor and energy of activation. The kinetic parameters of dehydration process of pure and L-arginine doped KDP crystals were evaluated by using the Coates and Redfern (1964) relation, which is as follows

$$
\begin{gathered}
\log _{10}\left[\left\{1-(1-\alpha)^{1-n}\right\} /\left\{T^{2}(1-n)\right\}\right]=\left\{\log _{10}[A R / \alpha E]\right. \\
[1-2 R T / E]\}-\{E / 2 \cdot 3 R T\},
\end{gathered}
$$

where $\alpha=\left(W_{0}-W\right) /\left(W_{0}-W_{\mathrm{f}}\right), W_{0}$ the initial weight, $W$ the weight at time $t, W_{\mathrm{f}}$ the final weight, $n$ the order of the reac- tion, $A$ the frequency factor, $E$ the activation energy of the reaction, $R$ a gas constant, and $a$ the heating rate in deg.C. $\mathrm{min}^{-1}$.

To determine the value of activation energy and order of reaction, a plot of $\log _{10}\left[\left\{1-(1-\alpha)^{1-n}\right\} /\left\{T^{2}(1-n)\right\}\right]$ vs $1 / T$ is drawn for different values of $n$. The best linear fit gives the correct value of $n$. The value of activation energy can be calculated from the slope of a linear plot. The value of frequency factor can be obtained from (1). However, (1) is applied for all values of $n$, except $n=1$. For $n=1$, a modified equation has been proposed (Coates and Redfern 1964).

Figure 9 shows the linear plot for Coates and Redfern relation for $0 \cdot 3 \%$ L-arginine doped KDP crystal for dehydration process. Table 2 compiles the values of activation energy, frequency factor and order of reaction. The values of activation energy and frequency factor decrease as the amount of L-arginine doping increases. The activation energy is considered as a barrier to be surmounted for reactant to combine to form the product. Hence the higher value of activation energy for pure KDP crystal indicates more stable nature. This can be verified from thermo- 


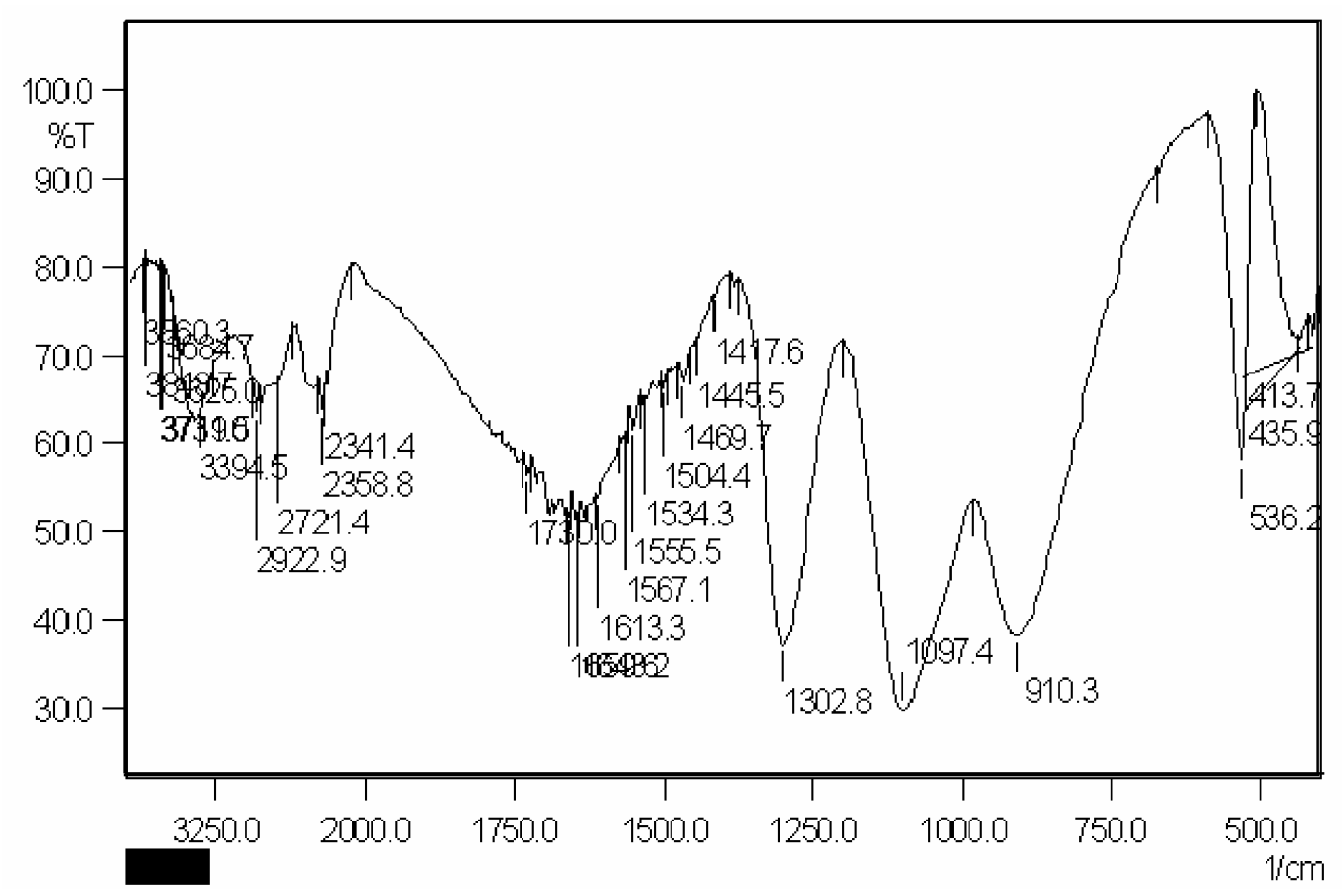

Figure 5. FTIR of $0.3 \% \mathrm{~L}$-arginine doped KDP crystal.

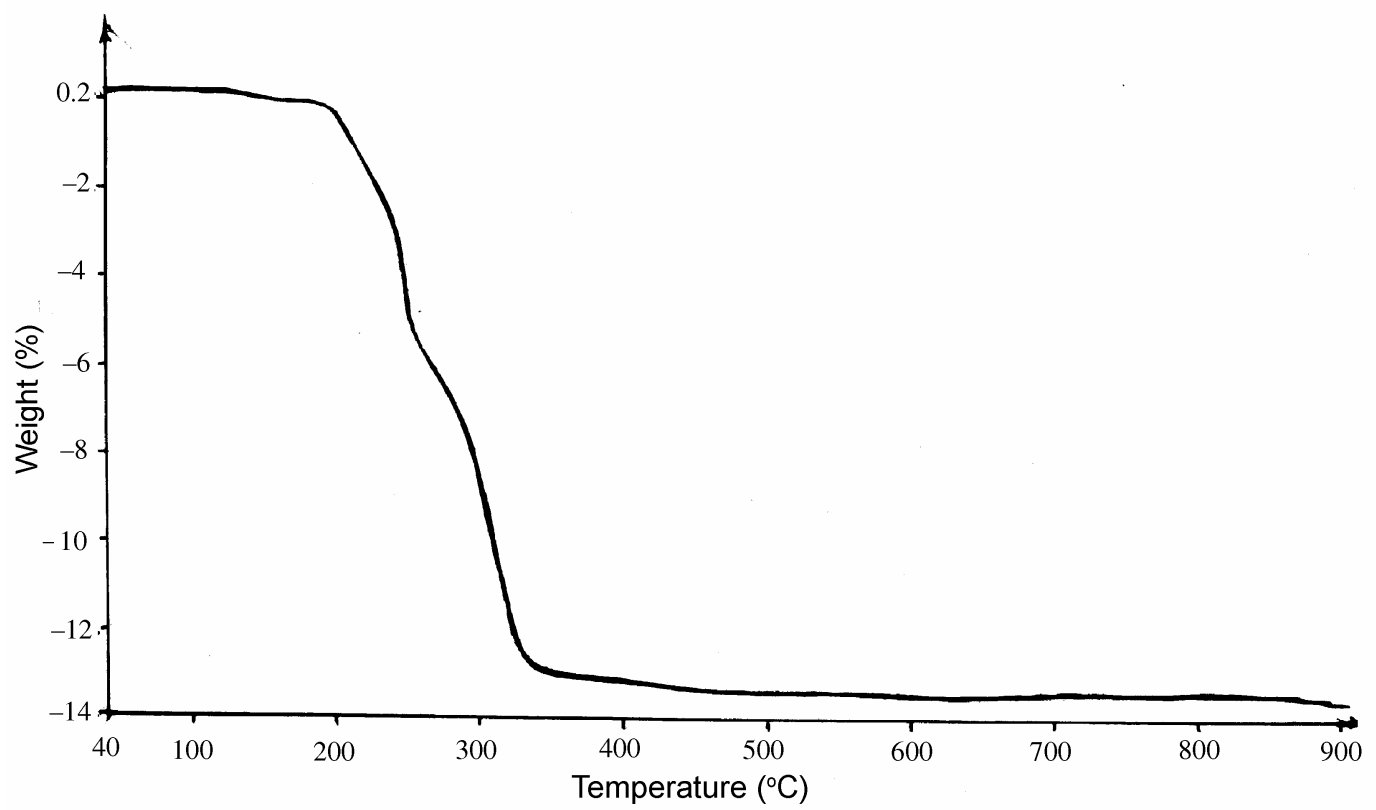

Figure 6. TGA of pure KDP crystal.

grams also. Various thermodynamic parameters have been evaluated for the dehydration process of pure and Larginine doped KDP crystals from the thermograms. Thermodynamic parameters are evaluated by the following expressions (Laidler 1987).

The standard entropy of activation, $\Delta^{\#} S^{\circ}$, is calculated from the following relation,

$$
\Delta^{\#} S^{\mathrm{o}}=2.303 \times R \times \log _{10}\left[A h / k T_{\mathrm{m}}\right],
$$

where $k$ is the Boltzmann constant, $h$ the Plank's constant, $T_{\mathrm{m}}$ the temperature and $A$ the frequency factor.

The standard enthalpy of activation, $\Delta^{\#} H^{\circ}$, can be calculated as follows,

$$
\Delta^{\#} H^{\mathrm{o}}=E-2 R T .
$$

The standard Gibbs energy of activation, $\Delta^{\#} G^{\circ}$, is estimated as follows, 


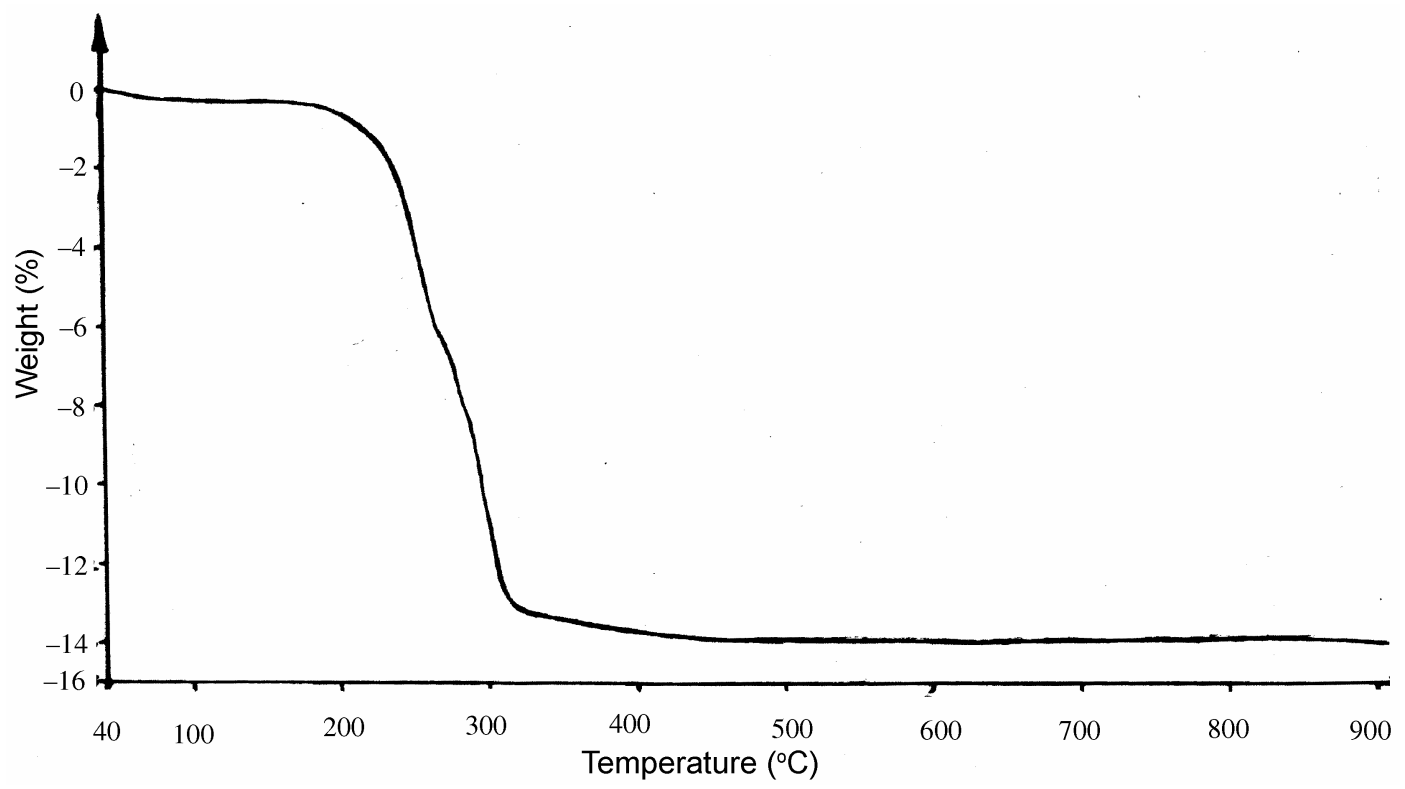

Figure 7. TGA of $0 \cdot 3 \%$ L-arginine doped KDP crystal.

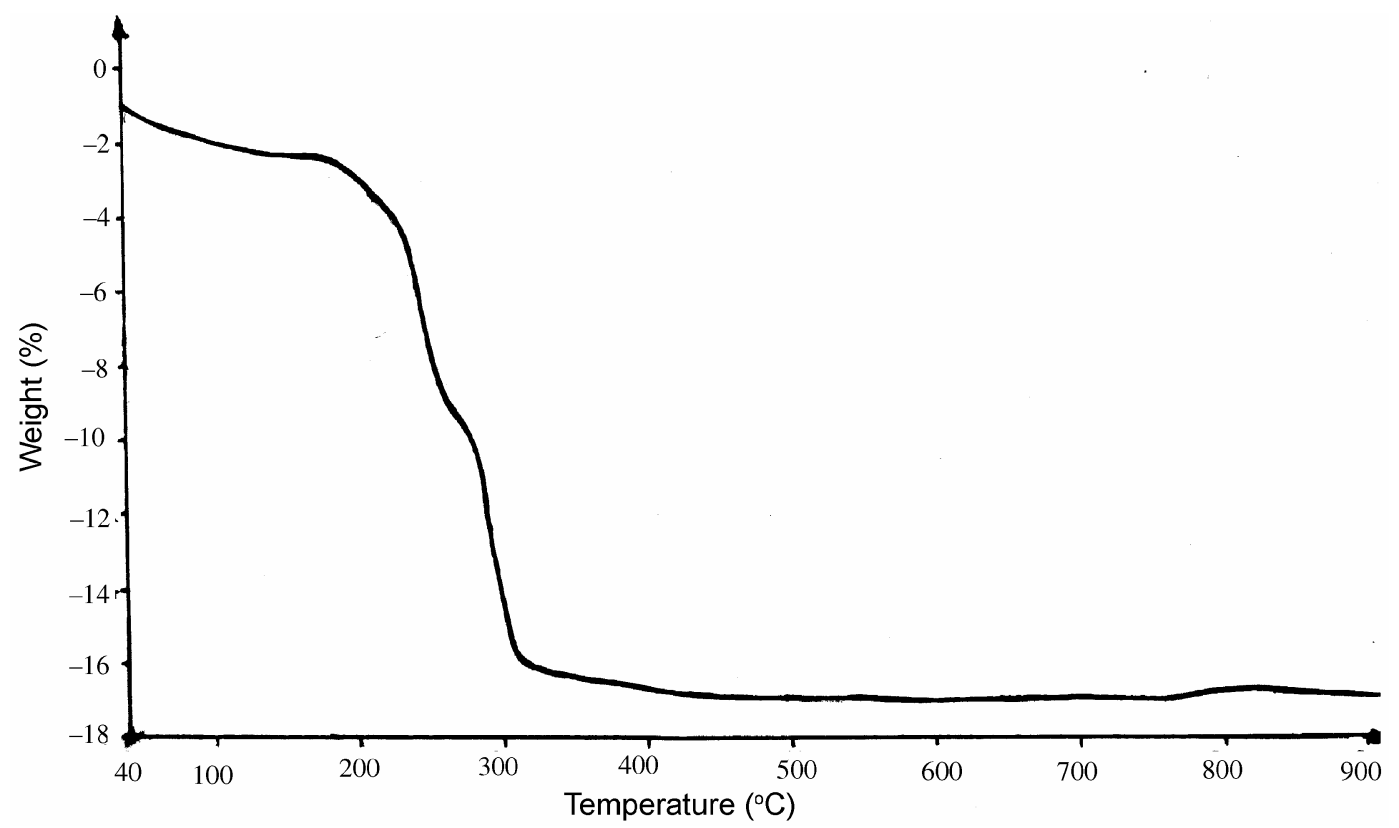

Figure 8. TGA of $0 \cdot 4 \%$ L-arginine doped KDP crystal.

Table 2. The kinetic parameters of dehydration.

\begin{tabular}{lccc}
\hline Samples & $\begin{array}{c}\text { Order of reaction } \\
(n)\end{array}$ & $\begin{array}{c}\text { Activation energy } \\
\left(\mathrm{kJ} \mathrm{mol}^{-1}\right)\end{array}$ & $\begin{array}{c}\text { Frequency factor } \\
(\mathrm{A})\end{array}$ \\
\hline Pure KDP crystal & $1 / 2$ & 103.82 & $3.237 \times 10^{21}$ \\
KDP + 0.3\% L-arginine & 0 & 71.98 & $1 \cdot 678 \times 10^{18}$ \\
KDP + 0.4\% L-arginine & 0 & 46.67 & $2.227 \times 10^{10}$ \\
\hline
\end{tabular}


Table 3. The thermodynamic parameters of dehydration.

\begin{tabular}{lccc}
\hline Samples & $\begin{array}{c}\text { Standard entropy } \\
\left(\mathrm{JK}^{-1} \mathrm{~mol}^{-1}\right)\end{array}$ & $\begin{array}{c}\text { Standard enthalpy } \\
\left(\mathrm{kJ} \mathrm{mol}^{-1}\right)\end{array}$ & $\begin{array}{c}\text { Gibbs free energy } \\
\left(\mathrm{kJ} \mathrm{mol}^{-1}\right)\end{array}$ \\
\hline Pure KDP crystal & $162 \cdot 25$ & $95 \cdot 25$ & 11.59 \\
KDP + 0.3\% L-arginine & $99 \cdot 34$ & $63 \cdot 33$ & 11.80 \\
KDP + 0.4\% L-arginine & $25 \cdot 20$ & $38 \cdot 11$ & $25 \cdot 13$ \\
\hline
\end{tabular}

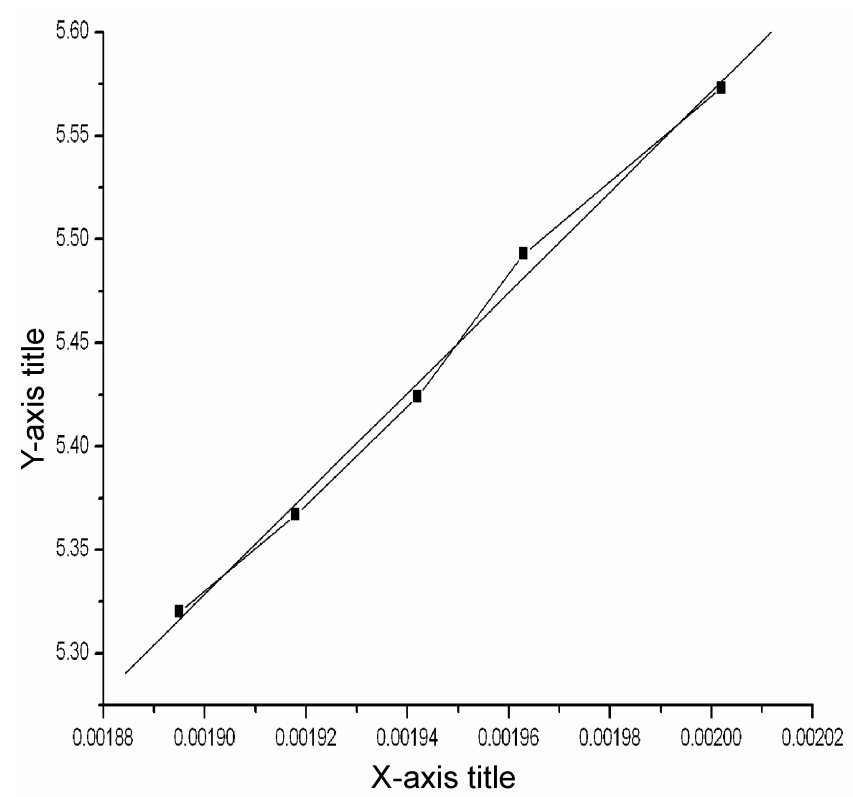

Figure 9. Plot of Coates and Redfern relation for $0 \cdot 3 \% \mathrm{~L}-$ arginine doped KDP crystal.

$$
\Delta^{\#} G^{\mathrm{o}}=\Delta^{\#} H^{\mathrm{o}}-T \Delta^{\#} S^{\mathrm{o}} .
$$

The kinetic and thermodynamic parameters are given in tables 2 and 3, respectively. It can be noted that on increasing doping of L-arginine in KDP, the value of standard entropy and standard enthalpy decreases, whereas the value of standard Gibbs energy increases. The processes are spontaneous or non-spontaneous types. In an isolated system, if a process being considered is attended by an increase in entropy $\left(\Delta^{\#} S^{\circ}\right)$, then it is known to be the spontaneous process, which occurs by itself (Whittaker et al 2001). The single crystalline nature of the sample is the most ordered form of the sample and dehydration of the sample brings the disorder in the sample, therefore, the large $\Delta^{\#} S^{\circ}$ is observed obviously in the case of pure KDP crystals than in the doped crystals.

\section{Conclusions}

Pure and L-arginine doped KDP crystals were grown by slow evaporation technique. FT-IR spectra and paper chromatography confirm the presence of amino acid, Larginine, in KDP crystals. Thermograms of pure and L- arginine doped KDP suggest that as the doping increases the crystals become thermally less stable and dehydrate faster at a comparatively lower temperature. The values of kinetic and thermodynamic parameters decrease with the amount of doping. The higher values of activation energy and standard entropy of activation suggest more stable condition for pure KDP than L-arginine doped KDP. The second harmonic signal strength and the second harmonic generation efficiency increase as the doping concentration of L-arginine increases.

\section{Acknowledgements}

The authors are thankful to UGC, New Delhi, for financial assistance under SAP. They also thank Dr P Sagayaraj, Loyola College, Chennai, Dr Das, Indian Institute of Science, Bangalore and Prof. K N Iyer, for their keen interest and support.

\section{References}

Ambujam K, Rajarajan K, Selvakumar S, Vetha Pother I, Joseph G P and Sagayaraj P 2006 J. Cryst. Growth B286 440

Ananda Kumari R and Chandramani R 2003 Bull. Mater. Sci. 26255

Aoki K, Kozo N and Iitaka Y 1971 Acta Crystallogr. B27 11

Coates A W and Redfern J P 1964 Nature 201183

Dabhi R M and Joshi M J 2003 Indian J. Phys. A76 481

De Yoreo J J 2002 Inst. Mater. Rev. 47113

Dixit V K, Rodrigues B V and Bhat H L 2001 Bull. Mater. Sci. 24455

Freeda T H and Mahadevan C 2000 Bull. Mater. Sci. 23335 Ittyachen R and Sagayaraj P 2002 J. Cryst. Growth 243356

Jaing M, Xu D and Tan Z 1983 Abstract of VII int. conference on crystal growth (Stuttgart, Germany: ICCG-VII) pp 2-67

Joshi V S and Joshi M J 2003 Cryst. Res. Technol. 38817

Karle I L and Karle J 1964 Acta Crystallogr. 17835

Krutz S K and Perry T T 1968 J. Appl. Phys. 393798

Kumaresan P, Moorthy Babu S and Anbarasan I M 2004 Abstract of XIV int. conference on crystal growth (Grenoble, France: ICCG-14) p 553

Laidler K J 1987 Chemical kinetics (New York: Harper and Row)

Lu G W and Sun X 2002 Cryst. Res. Technol. 3793

Meera K, Muralidharan R, Santhanaraghavan P, Gopalakrishnan R and Ramasamy P 2001 J. Cryst. Growth 226303

Mohan Kumar R, Muralidharan R, Jayavel R, Jayaraman D and Ramasamy P 2001 J. Cryst. Growth 229568 
Monaco S B, Davis L E, Velsko S P, Wang F T and Eimerl D 1987 J. Cryst. Growth 85252

Narayana Bhat M and Dharmaprakash S M 2002 J. Cryst. Growth 235511

Priya M, Padma C, Freeda T, Mahadevan C and Balasingh C 2001 Bull. Mater. Sci. 24511

Ramasamy S, Sridhar B, Ramakrishnan V and Rajaram R K 2001 Acta Crystallogr. E57 872

Singleton M F, Cooper J F and Anderson B D 1988 Appl. Phys. Lett. 52857

Sun X, Xu X, Wang Z, Gu O, Wang S, Li Y P, Fang C and Gao Z 2002 Cryst. Res. Technol. 3711
Wang Y S, Bennema P, Van der Linden W H, Boshaar J, Van Kessel J W M and Klapper H 1987 J. Cryst. Growth 83 471

Whittaker A G, Mount A R and Hill M R 2001 Physical chemistry (New Delhi: Viva)

Yan M S, Wu D X and Zeng J B 1986 J. Synth. Cryst. 151

Yokotani I, Sasaki T and Yoshida K 1988 Appl. Phys. Lett. 52 857

Zaitseva N P, De Yoreo J J and Dehaven M R 1997 J. Cryst. Growth 180255

Zaitseva N P, Carman L, Smolsky L, Torres R and Yan J 1999 J. Cryst. Growth 204512 